\title{
Pengaruh Disiplin Kerja dan Kompensasi Terhadap Kinerja Karyawan pada PT. Pertamina (Persero), Tbk. Pemasaran Region VII Makassar
}

\author{
Ali Wairooy \\ Politeknik Informatika Nasional Makassar \\ Email:wairooy@yahoo.co.id
}

\begin{abstract}
ABSTRAK
Penelitian ini bertujuan untuk menguji dan menganalisis pengaruh disiplin kerja dan kompensasi terhadap kinarja karyawan pada PT. Pertamina (Persero), Tbk. Pemasaran Region VII Makassar. Responden dalam penelitian ini adalah seluruh karyawan tetap PT. Pertamina (Persero), Tbk. Pemasaran Region VII Makassar. Berdasarkan metode sampel random, total sampel dalam penelitian ini adalah 49 responden. Dalam penelitian ini menggunakan data primer yang diperoleh dari penyebaran kuesioner. Jumlah kuesioner yang disebar sebanyak 49 eksemplar dan yang dapat kembali dan diolah sebanyak 49 eksempalar. Metode analisis yang digunakan dalam penelitian ini adalah analisis regresi linear berganda. Hasil penelitian menunjukkan bahwa disiplin kerja berpengaruh positif dan signifikan terhadap kinarja karyawan, kompensasi berpengaruh positif dan signifikan terhadap kinarja karyawan dan disiplin kerja dan kompensasi secara simultan berpengaruh positif dan signifikan terhadap kinarja karyawan. Hal ini berarti ketika disiplin kerja dan kompensasi tinggi maka kinerja karyawan akan meningkat.
\end{abstract}

Kata Kunci: Disiplin kerja, kompensasi dan kinerja karyawan.

\begin{abstract}
This study aims to examine and analyze the influence of work discipline and compensation for employee work at PT. Pertamina (Persero), Tbk. Marketing Region VII Makassar. Respondents in this research are all permanent employees of PT. Pertamina (Persero), Tbk. Marketing Region VII Makassar. Based on the random sample method, the total sample in this study was 49 respondents. In this study using primary data obtained from the distribution of questionnaires. The number of questionnaires distributed as many as 49 copies and which can be returned and processed as many as 49 eksempalar. The method of analysis used in this study is multiple linear regression analysis. The result of the research shows that work discipline has positive and significant effect to employee performance, the compensation has positive and significant effect on employee's work and work discipline and compensation simultaneously have positive and significant effect to employee's work. This means that when the discipline of work and high compensation then the performance of employees will increase.
\end{abstract}

Keywords: Work discipline, employee compensation and performance. 
16| Jurnal Administrare: Jurnal Pemikiran Ilmiah dan Pendidikan Administrasi Perkantoran, Vol. 4, No. 1, 2017

\section{PENDAHULUAN}

Perusahaan dalam usaha mencapai tujuannya sangat membutuhkan peran serta manusia yang menjadi anggota, perusahaan tidak akan berjalan tanpa adanya keterlibatan unsur manusia yang ada didalamnya (Liker, 2006; Poernomo \& Timur, 2006; Septianto, Septianto, \& Lataruva, 2011). Manusia merupakan unsur terpenting karena unsur-unsur lainnya yang dimiliki oleh suatu perusahaan seperti uang, materi, mesin-mesin, metode kerja, waktu dan kekayaan lainnya hanya dapat memberi manfaat bagi perusahaan jika manusia didalam perusahaan itu merupakan daya pembangunan dan bukan perusak bagi perusahaan.

Keberhasilan suatu perusahaan sangat dipengaruhi oleh kinerja karyawannya (Brahmasari \& Suprayetno, 2009; Devi, 2009; Suwati, 2013; Thoyib, 2005). Setiap perusahaan akan selalu berusaha untuk meningkatkan kinerja karyawannya, dengan harapan apa yang menjadi tujuan perusahaan akan tercapai. Bila suatu perusahaan mampu meningkatkan kinerja karyawannya, maka perusahaan akan memperoleh banyak keuntungan. Karyawan yang mempunyai kinerja tinggi, maka pekerjaannya akan lebih cepat diselesaikan, kerusakan akan dapat dikurangi, absensi akan dapat diperkecil, dan kemungkinan pemindahan karyawan dapat diperkecil seminimal mungkin (Trisnowati \& Budiwinarto, 2013).

Faktor yang mempengaruhi kinerja karyawan diantaranya adalah disiplin kerja seperti tujuan dan kemampuan, balas jasa, sanksi hukum, ketegasan serta hubungan kemanusiaan dan kompensasi seperti gaji, bonus dan tunjangan bagi karyawan berprestasi. Disiplin kerja merupakan suatu sikap menghormati, patuh dan taat pada peraturan-peraturan yang berlaku. Disiplin kerja sangat penting karena dengan karyawan yang mempunyai disiplin kerja maka akan menghasilkan kualitas kerja, kuantitas kerja dan waktu kerja yang baik sehingga dapat meningkatkan kinerja karyawan. Kompensasi merupakan sesuatu yang diterima karyawan sebagai pengganti kontribusi jasa mereka pada perusahaan (Baharuddin, Alhabsji, \& Utami, 2013). Pemberian kompensasi merupakan salah satu pelaksanaan fungsi manajemen sumber daya manusia yang berhubungan dengan semua jenis pemberian penghargaan individual sebagai pertukaran dalam melaksanakan tugas keorganisasian. Pemberian kompensasi haruslah adil dan layak bagi seorang karyawan. Artinya adil dan layak adalah bahwa sedapat mungkin kompensasi atau gaji yang diterima kelangsungan hidup karyawan dan pemberian kompensasi itu harus pula berdasarkan pada dasar kecilnya tanggung jawab dan risiko dari masing-masing pekerjaan sehingga dapat meningkatkan kinerja karyawan (Keraf, 2000; Tangkilisan, 2005; Tanjung, 2005; Yayu, n.d.).

Seorang karyawan yang memiliki kinerja tinggi dan baik dapat menunjang tercapainya tujuan dan sasaran yang telah ditetapkan oleh perusahaan. Kinerja merupakan perbandingan hasil kerja yang dicapai oleh karyawan dengan standar yang telah ditentukan (Arsyenda, 2013). Karyawan dapat bekerja dengan baik bila memiliki kinerja tinggi sehingga dapat menghasilkan kerja yang baik pula (Hirma, 2005). Dengan adanya kinerja yang tinggi yang dimiliki karyawan, diharapkan tujuan perusahaan dapat tercapai. Sebaliknya tujuan perusahaan susah atau bahkan tidak dapat tercapai bila karyawannya bekerja tidak memiliki kinerja yang baik sehingga tidak dapat menghasilkan kerja yang baik pula (Ariwibowo \& Nugraheni, 2011; Brahmasari \& Siregar, 2009; Reza \& Dirgantara, 2010; Sukmawati, 2008). 
Fenomena penelitian yang terkait pada disiplin kerja dan kompensasi terhadap kinerja karyawan PT. Pertamina (Persero), Tbk. Pemasaran Region VII Makassar ditemukan bahwa penerapan disiplin kerja belum optimal, dimana masih ada karyawan yang belum mentaati disiplin kerja seperti: jam kerja, mereka masuk kerja setelah jam 09.00 Wita dan pulang sebelum jam 17.00 Wita, disamping itu sikap karyawan yang tidak memegang teguh amanah dalam melaksanakan tugas pokok dan kewajibannya sebagai karyawan. Tindakan-tindakan seperti tersebut di atas dapat berakibat pada kurangnya pelayanan kepada masyarakat. Selain itu, fenomena kompensasi terhadap kinerja karyawan belum optimal, dimana kompensasi yang diberikan PT. Pertamina (Persero), Tbk. Pemasaran Region VII Makassar adalah kompensasi finansial maupun non finansial, namun ada halnya pemberian kompensasi dianggap kurang adil dan tidak setingkat dengan apa yang mereka kerjakan. Misalnya karyawan yang memiliki kelas jabatan 11 yang dari peraturan perusahaan jelas memiliki kompensasi ataupun tunjangan yang lebih besar dibandingkan dengan karyawan yang kelas jabatannya 12. Sedangkan dalam tanggung jawab atau pemberian pekerjaan biasanya kelas jabatan 12 mendapat tanggung jawab pekerjaan yang lebih banyak dibandingkan dengan kelas jabatan 11. Hal inilah yang sering mengakibatkan karyawan merasa pemberian kompensasi tidak adil yang berakibat pada kinerja mereka yang menurun (Hasil wawancara dengan beberapa karyawan pada Direktorat SDM dan Umum PT. Pertamina (Persero), Tbk. Pemasaran Region VII Makassar pada saat dilakukannya pra penelitian).

Beberapa hasil penelitian yang telah dilakukan sebelumnya, Trisnowati \& Budiwinarto (2013), melakukan penelitian mengenai pengaruh disiplin kerja dan kompensasi terhadap kinerja karyawan pada PT. Herculon Carpet Semarang. Hasil penelitian disiplin kerja dan kompensasi berpengaruh positif dan signifikan terhadap kinerja karyawan. (Arsyenda, 2013), melakukan penelitian mengenai pengaruh disiplin kerja dan kompensasi terhadap kinarja karyawan pada PT. Tambang Batu Bara di Palembang. Hasil penelitian disiplin kerja dan kompensasi berpengaruh positif dan signifikan terhadap kinarja karyawan. Labudo (2013) melakukan penelitian mengenai disiplin kerja dan kompensasi pengaruhnya terhadap produktivitas karyawan. Hasil penelitian menunjukakn secara simultan dan parsial disiplin kerja dan kompensasi berpengaruh terhadap terhadap produktivitas karyawan namun dalam penelitian Arianto (2013) melakukan penelitian mengenai pengaruh disiplin kerja dan budaya kerja terhadap kinarja karyawan. Hasil penelitian tersebut menunjukkan disiplin kerja tidak berpengaruh signifikan terhadap kinarja karyawan, sedangkan budaya kerja berpengaruh positif dan signifikan terhadap kinarja karyawan.

\section{METODE PENELITIAN}

Peneliltian ini adalah penelitian kuantitatif. Jenis data yang digunakan dalam penelitian ini adalah data yang diperoleh dari tanggapan responden terhadap angket/kuesioner yang diberikan (Ruslan, 2004). Sumber data penelitian ini adalah data primer yaitu data yang diperoleh secara langsung dari responden melalui penyebaran kuesioner. Teknik pengumpulan dalam penelitian ini menggunakan kuesioner. Kesioner yang penulis gunakan adalah kuesioner tertutup, suatu cara pengumpulan data dengan memberikan atau meyebarkan daftar pernyataan 
18| Jurnal Administrare: Jurnal Pemikiran Ilmiah dan Pendidikan Administrasi Perkantoran, Vol. 4, No. 1, 2017

kepada responden. Populasi dalam penelitian ini adalah seluruh karyawan tetap PT. Pertamina (Persero), Tbk. Pemasaran Region VII Makassar sebanyak 95 orang. Penarikan sampel yang digunakan dalam penelitian ini adalah simpel random sampling yaitu pengambilan sampel dengan cara acak sederhana melalui daftar bilangan random, sehingga setiap elemen populasi mempunyai kesempatan yang sama untuk terpilih menjadi anggota sampel yang akan diteliti dengan mengambil 49 orang responden / karyawan sebagai sampel dengan menyiapkan daftar pertanyaan (kuesioner). Analisis statistik inferensial yang digunakan untuk menjawab masalah dan sekaligus menguji hipotesis.

\section{HASIL DAN PEMBAHASAN}

\section{Analisis Data}

Berdasarkan data yang diperoleh dalam penelitian, maka hasil pengujian validitas instrument penelitian yang dapat dilihat pada tabel 1.

\section{Tabel 1}

Hasil Uji Validitas Variabel Penelitian

\begin{tabular}{|l|c|c|c|c|}
\hline Variabel & Item & $\begin{array}{c}\text { Corrected } \\
\text { Item Total } \\
\text { Correlation }\end{array}$ & R Standar & Keterangan \\
\hline 1. Disiplin Kerja (X1) & DK1 & 0,625 & 0,30 & Valid \\
& DK2 & 0,742 & 0,30 & Valid \\
& DK3 & 0,634 & 0,30 & Valid \\
2. Kompensasi (X2) & DK4 & 0,542 & 0,30 & Valid \\
& K1 & 0,395 & 0,30 & Valid \\
3. Kinerja Karyawan (Y) & K2 & 0,691 & 0,30 & Valid \\
& K3 & 0,604 & 0,30 & Valid \\
& KK1 & 0,577 & 0,30 & Valid \\
& KK2 & 0,657 & 0,30 & Valid \\
& KK3 & 0,611 & 0,30 & Valid \\
& KK4 & 0,548 & 0,30 & Valid \\
\hline
\end{tabular}

Sumber: Data Primer setelah diolah, 2017

Berdasarkan tabel 1 di atas, dapat diketahui bahwa dari 3 variabel yang diteliti yakni disiplin kerja, kompensasi dan kinerja karyawan dengan jumlah item sebanyak 11 item pernyataan yang diajukan, nampak bahwa semua item pernyataan sudah valid, karena memiliki nilai corrected item total correlation yang sudah di atas dari 0,30 . Hasil uji normalitas dapat dilihat pada tabel 2. Yang menunjukkan bahwa uji multikolineritas antar kedua variabel karena nilai VIF kurang dari 10 dan lebih besar dari 0,10. 
Tabel 2

Uji Multikolineritas

\begin{tabular}{|l|c|c|c|}
\hline \multicolumn{1}{|c|}{ Variabel bebas } & Tolerance & VIF & Keterangan \\
\hline & 0,954 & 1,672 & Non multikolineritas \\
Disiplin Kerja (X1) & 0,958 & 1,707 & Non multikolineritas \\
Kompensasi (X2) & & & \\
\hline
\end{tabular}

Sumber: Data Primer setelah diolah, 2017

Sedangkan analisis statistik inferensial dilakukan dengan menggunakan alat statistik regresi linear berganda untuk menguji dan menganalisis pengaruh disiplin kerja dan kompensasi terhadap kinerja karyawan. Seperti yang digambarkan pada tabel 3.

Tabel 3

Hasil Pengujian Regresi Linear Berganda

\begin{tabular}{|c|c|c|c|c|}
\hline Variabel & & $\begin{array}{l}\text { Koefisien } \\
\text { Regresi }\end{array}$ & t-Hitung & Sig. \\
\hline Constant & & 1,382 & & \\
\hline Disiplin Kerja (X1) & & .264 & 2,230 & .029 \\
\hline Kompensasi (X2) & & .423 & 4,422 & .000 \\
\hline \multicolumn{5}{|c|}{ Tingkat Signifikan $\alpha=0,05$ atau $5 \%$} \\
\hline \multicolumn{5}{|c|}{$\mathrm{R}=0.725$} \\
\hline \multicolumn{5}{|l|}{$\mathrm{R}^{2}=0,526$} \\
\hline F-hitung $=15,124$ & Siq & 0,000 & & \\
\hline $\mathrm{F}$ tabel $=3,20$ & t-tabel : & 1,943 & & \\
\hline
\end{tabular}

Sumber: Data Primer setelah diolah dengan SPSS, 2017

Berdasarkan tabel 3, diperoleh persamaan regresi linear berganda berikut: $\mathrm{Y}=1,382+0,264 \mathrm{X} 1+0,423 \mathrm{X} 2$

Memperhatikan nilai koefisien arah dari masing-masing variabel bebas (X1 s/d X2) pada persamaan regresi linear berganda di atas maka nilai konstanta dan nilai koefisien arah (X1s/d X2 dapat dijelaskan sebagai berikut: 
20| Jurnal Administrare: Jurnal Pemikiran Ilmiah dan Pendidikan Administrasi Perkantoran, Vol. 4, No. 1, 2017

$\mathrm{a}=1,382$ yang merupakan nilai konstanta artinya, bahwa tanpa adanya disiplin kerja dan kompensasi maka kinerja karyawan sebesar 1,382\%.

$\mathrm{b}_{1}=0,264$, artinya penambahan frekuensi disiplin kerja sebesar satu satuan akan menyebabkan

kinerja karyawan meningkat sebesar $0,264 \%$.

$\mathrm{b}_{2}=0,423$, artinya penambahan frekuensi kompensasi sebesar satu satuan akan menyebabkan

kinerja karyawan meningkat sebesar $0,423 \%$.

\section{Hasil Pengujian Hipotesis}

\section{Uji Simultan (Uji F)}

Uji simultan (uji F), digunakan untuk menguji apakah variabel independen (X1s/d X2) secara simultan/bersama-sama berpengaruh terhadap variabel dependen (Y), nilai $\mathrm{F}$ hitung sebesar 15,124 lebih besar dari $\mathrm{F}$ tabel sebesar $(15,124>3,20)$ dan signifikansinya sebesar 0,000 lebih kecil dari $\alpha=0,05(0,000<0,05)$. Hal ini membuktikan bahwa variabel bebas secara simultan atau bersama-sama berpengaruh positif dan signifikan terhadap variabel tidak bebasnya sehingga dapat ditarik kesimpulan bahwa hipotesis nol (H0) ditolak dan hipotesis alternatif (Ha) diterima.

\section{Uji Parsial (Uji t)}

Uji parsial (uji t), digunakan untuk mengetahui masing-masing variabel independen (X1 s/d X2) terhadap variabel dependen (Y) sebagai berikut:

1. Variabel disiplin kerja $(\mathrm{X} 1)$, nilai thitung $>$ ttabel $=2,230>1,943$ dan signifikansinya 0,029 $<0,05$, Sehingga dapat ditarik kesimpulan bahwa hipotesis nol (H0) ditolak dan hipotesis alternatif (Ha) diterima yang menunjukkan bahwa variabel disiplin kerja (X1) secara parsial (sendiri-sendiri) berpengaruh positif dan signifikan terhadap kinerja karyawan (Y).

2. Variabel kompensasi (X2), nilai thitung $>$ ttabel $=4,422>1,943$ dan signifikansinya 0,000 $<0,05$, sehingga dapat ditarik kesimpulan bahwa hipotesis nol (H0) ditolak dan hipotesis alternatif (Ha) diterima yang menunjukkan bahwa variabel kompensasi (X2) secara parsial berpengaruh positif dan signifikan terhadap kinerja karyawan $(\mathrm{Y})$.

\section{Uji Koefisien Determinasi $\left(\mathbf{R}^{2}\right)$}

Uji koefisien determinasi $\left(\mathrm{R}^{2}\right)$, digunakan untuk melihat besarnya pengaruh disiplin kerja dan kompensasi terhadap kinerja karyawan dimana nilai $\mathrm{R}^{2}$ adalah 0,526 atau 52,6\% yang berarti ada 52,6\% yang dapat didekati oleh persamaan regresi tersebut, dengan kata lain sebanyak 52,6\% variabel bebas (disiplin kerja dan kompensasi) dapat memberikan kontribusi terhadap variabel tidak bebas (kinerja karyawan) sedangkan sisanya 47,4\% (100\% - 52,6\%) dipengaruhi oleh faktor lain yang tidak diteliti. Penjelasan tersebut, menunjukkan bahwa $\mathrm{R}^{2}$ 
semakin besar (mendekati satu), maka dapat dikatakan bahwa pengaruh variabel disiplin kerja (X1) dan kompensasi (X2) adalah besar atau semakin kuat terhadap variabel kinerja karyawan (Y).

\section{Pembahasan}

\section{Pengaruh disiplin kerja terhadap kinarja karyawan}

Hasil penelitian ini menunjukkan bahwa disiplin kerja berpengaruh positif dan signifikan terhadap kinarja karyawan. Positif terlihat dari koefisien regresi sebesar 0,264 dan signifikan yang dilihat dari signifikansi $(0,029)$ lebih kecil dari taraf signifikansi yang disyaratkan sebesar $5 \%(0,05)$. Berpengaruh secara positif artinya ketika disiplin kerja tinggi maka kinerja karyawan akan meningkat. Berpengaruh secara signifikan artinya dengan adanya disiplin kerja yang tinggi dapat meningkatkan kinerja karyawan.Disiplin kerja juga berpengaruh positif dan signifikan terhadap kinerja karyawan yang ditunjukkan oleh thitung lebih besar dari ttabel $(2,230>1,943)$ dan tingkat signifikansinya lebih kecil dari $0,05(0,029<0,05$. Hal ini membuktikan hipotesis penelitian bahwa disiplin kerja berpengaruh positif dan signifikan terhadap kinarja karyawan pada PT. Pertamina (Persero), Tbk. Pemasaran Region VII Makassar. Hasil penelitian ini sejalan dengan penelitian Trisnowati (2013), dengan judul penelitian "pengaruh disiplin kerja dan kompensasi terhadap kinerja karyawan, hasil penelitiannya menjelaskan bahwa disiplin kerja dan kompensasi berpengaruh positif dan signifikan terhadap kinerja karyawan. Hal ini menunjukkan bahwa disiplin kerja yang tinggi dapat meningkatkan kinerja karyawan.

\section{Pengaruh kompensasi terhadap kinarja karyawan}

Hasil penelitian ini menunjukkan bahwa kompensasi berpengaruh positif dan signifikan terhadap kinarja karyawan. Positif terlihat dari koefisien regresi sebesar 0,423 dan signifikan yang dilihat dari signifikansi $(0,000)$ lebih kecil dari taraf signifikansi yang disyaratkan sebesar 5\% $(0,05)$. Berpengaruh secara positif artinya ketika kompensasi tinggi maka kinerja karyawan akan meningkat. Berpengaruh secara signifikan artinya dengan adanya kompensasi yang tinggi dapat meningkatkan kinerja karyawan. Kompensasi juga berpengaruh positif dan signifikan terhadap kinerja karyawan yang ditunjukkan oleh thitung lebih besar dari ttabel $(4,422>1,943)$ dan tingkat signifikansinya lebih kecil dari $0,05(0,000<0,05$. Hal ini membuktikan hipotesis penelitian bahwa kompensasi berpengaruh positif dan signifikan terhadap kinarja karyawan pada PT. Pertamina (Persero), Tbk. Pemasaran Region VII Makassar. Hasil penelitian ini sejalan dengan penelitian Arsyenda (2013), dengan judul penelitian "pengaruh disiplin kerja dan kompensasi terhadap kinerja karyawan, hasil penelitiannya menjelaskan bahwa disiplin kerja dan kompensasi berpengaruh positif dan signifikan terhadap kinerja karyawan. Hal ini menunjukkan bahwa kompensasi yang tinggi dapat meningkatkan kinerja karyawan.

\section{Pengaruh disiplin kerja dan kompensasi terhadap kinerja karyawan}


Hasil penelitian ini menunjukkan bahwa disiplin kerja dan kompensasi secara simultan (bersama-sama) berpengaruh positif dan signifikan terhadap kinerja karyawan. Positif terlihat dari Fhitung sebesar 15,124 lebih besar dari Ftabel sebesar 3,20 (15,124> 3,20) dan signifikan yang dilihat dari signifikansi $(0,000)$ lebih kecil dari taraf signifikansi yang disyaratkan sebesar $5 \%$ atau $0,05(0,000<0,05)$. Berpengaruh secara positif menunjukkan bahwa disiplin kerja dan kompensasi sejalan dengan kinerja karyawan artinya ketika disiplin kerja dan kompensasi tinggi maka kinerja karyawan akan meningkat. Berpengaruh secara signifikan artinya dengan adanya disiplin kerja dan kompensasi yang tinggi dapat meningkatkan kinerja karyawan. Hal ini membuktikan hipotesis penelitian bahwa disiplin kerja dan kompensasi secara simultan berpengaruh positif dan signifikan terhadap kinarja karyawan pada PT. Pertamina (Persero), Tbk. Pemasaran Region VII Makassar. Hasil penelitian ini sejalan dengan penelitian Trisnowati (2013), dengan judul penelitian "pengaruh disiplin kerja dan kompensasi terhadap kinerja karyawan, hasil penelitiannya menjelaskan bahwa disiplin kerja dan kompensasi berpengaruh positif dan signifikan terhadap kinerja karyawan. Hal ini menunjukkan bahwa disiplin kerja dan kompensasi yang tinggi dapat meningkatkan kinerja karyawan.

\section{SIMPULAN}

1. Variabel disiplin kerja berpengaruh positif dan signifikan terhadap kinerja karyawan pada PT. Pertamina (Persero), Tbk. Pemasaran Region VII Makassar, hal ini dibuktikan secara statistik thitung > ttabel dan tingkat signifikansinya lebih kecil dari taraf signifikansi yang disyaratkan.

2. Variabel kompensasi berpengaruh positif dan signifikan terhadap kinerja karyawan pada PT. Pertamina (Persero), Tbk. Pemasaran Region VII Makassar, hal ini dibuktikan secara statistik thitung $>$ ttabel dan tingkat signifikansinya lebih kecil dari taraf signifikansi yang disyaratkan.

3. Variabel disiplin kerja dan kompensasi secara simultan berpengaruh positif dan signifikan terhadap kinarja karyawan pada PT. Pertamina (Persero), Tbk. Pemasaran Region VII Makassar, hal ini dibuktikan secara statistik Fhitung > Ftabel dan tingkat signifikansinya lebih kecil dari taraf signifikansi yang disyaratkan. Variabel kompensasi yang paling dominan berpengaruh alasannya adalah karena memiliki nilai koefisien regresi dan nilai thitung yang terbesar jika dibandingkan dengan disiplin kerja.

\section{DAFTAR PUSTAKA}

Arianto, D. A. N. (2013). Pengaruh kedisiplinan, lingkungan kerja dan budaya kerja terhadap kinerja tenaga pengajar. Jurnal Economia, 9(2), 191-200.

Ariwibowo, R. N., \& Nugraheni, R. (2011). Pengaruh Kepemimpinan, Motivasi dan Lingkungan Kerja Fisik Terhadap Kinerja Karyawan (Studi Pada CV. Karya Mina Putra Rembang Devisi Kayu). Universitas Diponegoro.

Arsyenda, Y. (2013). Pengaruh Motivasi Kerja Dan Disiplin Kerja Terhadap Kinerja PNS 
Ali Wairooy, Pengaruh Disiplin Kerja dan Kompensasi Terhadap Kinerja Karyawan pada PT. Pertamina

(Persero), Tbk. Pemasaran Region VII Makassar $\mid 23$

(Studi Kasus: BAPPEDA Kota Malang). Malang: Fakultas Ekonomi Dan Bisnis Universitas Brawijaya.

Baharuddin, A., Alhabsji, T., \& Utami, H. N. (2013). Pengaruh Pelatihan, Kompensasi dan Disiplin Kerja Terhadap Prestasi Kerja Karyawan (Studi Pada Kantor PT. PLN (Persero) Area Pelayanan dan Jaringan Malang). PROFIT (JURNAL ADMINISTRASI BISNIS), 6(2).

Brahmasari, I. A., \& Siregar, P. (2009). Pengaruh Budaya Organisasi, Kepemimpinan Situasional dan Pola Komunikasi terhadap Disiplin Kerja dan Kinerja Karyawan pada PT. Central Proteinaprima Tbk. Jurnal Aplikasi Manajemen-Journal of Applied Management, 7(1), 238-250.

Brahmasari, I. A., \& Suprayetno, A. (2009). Pengaruh Motivasi Kerja, Kepemimpinan dan Budaya Organisasi Terhadap Kepuasan Kerja Karyawan serta Dampaknya pada Kinerja Perusahaan (Studi kasus pada PT. Pei Hai International Wiratama Indonesia). Jurnal Manajemen Dan Kewirausahaan, 10(2), pp-124.

Devi, E. K. D. (2009). Analisis Pengaruh Kepuasan Kerja Dan Motivasi Terhadap Kinerja Karyawan Dengan Komitmen Organisasional Sebagai Variabel Intervening (Studi Pada Karyawan Outsourcing PT SEMERU KARYA BUANA Semarang). Program Pasca Sarjana Universitas Diponegoro.

Hirma, D. (2005). Manajemen Kinerja.

Keraf, A. S. (2000). Pustaka Filsafat ETIKA BISNIS, Tuntunan dan Relevansinya. Kanisius.

Labudo, Y. (2013). Disiplin Kerja Dan Kompensasi Pengaruhnya Terhadap Produktivitas Karyawan. JURNAL RISET EKONOMI, MANAJEMEN, BISNIS DAN AKUNTANSI, 1(3).

Liker, J. (2006). The Toyota way fieldbook. Esensi.

Poernomo, E., \& Timur, A. B. U. P. N. V. J. (2006). Pengaruh Kreativitas Dan Kerjasama Tim Terhadap Kinerja Manajer Pada PT. Jesslyn K Cakes Indonesia Cabang Surabaya. Jurnal Ilmu-Ilmu Ekonomi, 6(2), 102-108.

Reza, R. A., \& Dirgantara, I. (2010). Pengaruh gaya kepemimpinan, motivasi dan disiplin kerja terhadap kinerja karyawan PT Sinar Santosa Perkasa Banjarnegara. Universitas Diponegoro.

Ruslan, R. (2004). Metode penelitian. Jakarta: PT Raja Grafindo.

Septianto, D., Septianto, D., \& Lataruva, E. (2011). Pengaruh Lingkungan kerja dan stres Kerja Terhadap Kinerja Karyawan Studi pada PT Pataya Raya Semarang. Universitas Diponegoro.

Sukmawati, F. (2008). Pengaruh Kepemimpinan, Lingkungan Kerja Fisik, dan Kompensasi terhadap Kinerja Karyawan di PT. Pertamina (Persero) UPMS III Terminal TransitUtama Balongan Indramayu. Jurnal Ekonomi Dan Bisnis, 2(2), 175-191.

Suwati, Y. (2013). Pengaruh Kompensasi dan Motivasi Kerja Terhadap Kinerja Karyawan Pada PT. Tunas Hijau Samarinda. Jurnal Ilmu Administrasi Bisnis, 1(1), 41-55.

Tangkilisan, H. N. S. (2005). Manajemen publik. Grasindo.

Tanjung, A. (2005). Pengaruh Kompensasi Terhadap Motivasi Kerja Karyawan Bagian Personalia PT Agronesia Divisi Industri Makanan Dan Minuman Bandung. Universitas Widyatama.

Thoyib, A. (2005). Hubungan Kepemimpinan, Budaya, Strategi, dan Kinerja: Pendekatan 
$24 \mid$ Jurnal Administrare: Jurnal Pemikiran Ilmiah dan Pendidikan Administrasi Perkantoran, Vol. 4, No. 1, 2017

Konsep. Jurnal Manajemen Dan Kewirausahaan, 7(1), pp-60.

Trisnowati, J., \& Budiwinarto, K. (2013). Kajian Pengaruh Harga dan Pendapatan terhadap

Proporsi Pengeluaran Makanan Rumah Tangga (Pendekatan Model Linier Permintaan Lengkap). In Prosiding Seminar Nasional Statistika Universitas Dipenegoro 2013 ISBN: 978-602-14387-0 (Vol. 1).

Yayu, H. (n.d.). Sistem Kompensasi Di Madrasah Al-Ihsan Pandeglang Banten. 